\title{
Transmission Performance of Optical Add/Drop Multiplexers in Metro Optical Access Communication Networks
}

\author{
Omima El-kailani \\ Electrical and Electronic Engineering \\ University of Benghazi, Libya
}

\author{
Mohmoud Al-aujali \\ Electrical and Electronic Engineering \\ University of Benghazi, Libya
}

\begin{abstract}
As multimedia domains develop, metro access networks are desired to allow for flexible configuration changes as well as higher speed and capacity. An optical network configuration that combines optical add/drop multiplexers (OADMs) with wavelength division multiplexing (WDM) system began to be introduced in these networks for its suitability.

This paper presents the performance analysis of the optical add/drop multiplexer (OADM) on the Q-factor, and eye opening of the eye diagram over wide range of varying parameters. The transmission Performance over fiber transmission system is considering impact of: add/drop channels, transmitted and received power, fiber length, and frequency spacing. Among the important results obtained is the fact that as the received power increases, the $\mathrm{Q}$ factor also increases; until a certain level the $\mathrm{Q}$ factor reaches the saturation and would be constant no matter how much the power is increased. Thus, any power added after this point is a wasted power. In addition, the performance characteristics of the OADMs, which are capable of dealing with one to several channels arbitrarily selected, were analyzed.
\end{abstract}

\section{Keywords}

Wavelength division multiplexing (WDM), optical add/drop multiplexer (OADM), Quality factor (Q factor), Bit error rate (BER), Metro access network, Transmission performance.

\section{INTRODUCTN}

Optical networks provides enormous capacity, as well as a common infrastructure over which a variety of services can be delivered. These networks are also becoming capable of delivering bandwidth in a flexible manner where and when needed [1]. Fiber transmission technology has evolved over the past few decades to offer higher and higher bit rates on a fiber over longer and longer distances. This tremendous growth in bandwidth is primarily due to the deployment of optical fiber communication systems [2].

Optics is clearly the preferred means of transmission, and wavelength division multiplexing (WDM) is the favorite multiplexing technology for practical optical communication networks, since all of the end-user equipment needs to operate only at the bit rate of a WDM channel, which can be chosen arbitrarily, e.g., peak electronic processing speed [3]. From both technical and economic perspectives, the ability to provide

Potentially unlimited transmission capacity is the most obvious advantage of WDM technology [4]. What makes the employment of passive optical architectures in the access network largely recognized is that the WDM devices are available in the marketplace and easy to implement. In fact, WDM light wave systems were available commercially by 1996, and their total capacity exceeded $1.6 \mathrm{~Tb} / \mathrm{s}$ by the year 2000 [5].

Today we are seeing the development of high-capacity amplified terabits/second WDM systems with hundreds of channels at $10 \mathrm{~Gb} / \mathrm{s}$ or more, with channel spacing as low as $50 \mathrm{GHz}$, over very long transmission spans [6] .The optical add-drop multiplexer is one of the key components for WDM optical networks, because WDM systems send signals from several sources over a single fiber, so between multiplexing and demultiplexing points there is an area in which multiple wavelengths exist. It is often desirable to be able to remove or insert one or more wavelengths at some point. An optical add/drop multiplexer (OADM) performs this function. Rather than combining or separating all wavelengths, the OADM can remove some while passing others on. OADMs are a key part of moving toward the goal of all-optical networks [7].

In general, OADM provides great flexibility in building networks. For example, if there is a network node at which most of the traffic is to be passed through and a small fraction is to be dropped and added, it may be more cost-effective to use a WDM optical add/drop element than terminating all the traffic and doing the add/drop in the electrical domain [8]. The desirable bit error rate (BER) required for all light wave systems $<10^{-9}$ or $10^{-12}$. In optical system the BER is typically too small to measure, hence Q-factor is more suitable to be used. A convenient relationship to bear in mind is that a BER of $10^{\wedge-9}$ requires $Q$ factor of $15.6 \mathrm{~dB}$ (or a linear ratio of 6) [9].

\section{SIMULATION AND RESULTS}

In this paper the transmission performances of the OADM was investigated over wide range of parameters, considering the effect of adding/dropping different channels, the effect of the fiber length on the received power, the effect of the channel spacing between transmitted channels, and the effect of the received power on the Q factor. All simulations were done with a commercially available software packaged from OPTIWAVE called OPTISYSTEM, and all graphs were plotted using KALEIDAGRAPH software.

\subsection{The Effect of Adding/dropping Different Channels}

The simulated Q-factor of the added/dropped channels is shown in Fig. 1. The performance of the system was at 100 $\mathrm{km}, 50 \mathrm{GHz}$ spacing. It can be seen that the channel where adding/dropping occurs, has the lowest $\mathrm{Q}$ factor. 


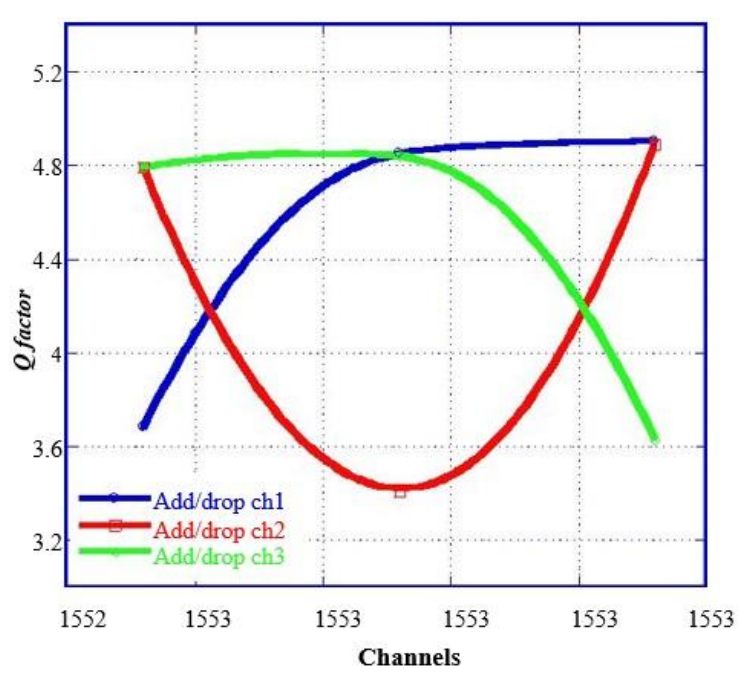

Fig. 1: The $Q$ factor of the added/dropped Channels at $50 \mathrm{GHz}$ spacing

\subsection{The Relation between Received Power and the $Q$ factor}

The simulation results of the Q-factor versus received power is presented in table 1 . The performance of the system was at $50 \mathrm{Km}$. It is seen from Fig.2 that as we increase the received power the $\mathrm{Q}$ factor also increases, until a certain value, the $\mathrm{Q}$ factor reaches the saturation and would be constant no matter how much the power is increased.

Table 1. The $Q$ factor of all channels

\begin{tabular}{|c|c|c|c|c|}
\hline $\begin{array}{c}\text { Received } \\
\text { power } \\
(\mathbf{d b m})\end{array}$ & $\begin{array}{c}\text { Q factor } \\
\text { (ch1) }\end{array}$ & $\begin{array}{c}\text { Q factor } \\
(\mathbf{c h 2})\end{array}$ & $\begin{array}{c}\text { Q factor } \\
\text { (ch3) }\end{array}$ & $\begin{array}{c}\text { Q factor } \\
(\mathbf{c h} \text { ) }\end{array}$ \\
\hline-22.617 & 7.28 & 8.949 & 9.976 & 9.34 \\
\hline-20.617 & 11.4 & 13.927 & 15.71 & 14.019 \\
\hline-17.6 & 21.4 & 26.27 & 29.575 & 27.61 \\
\hline-13.6 & 42.1 & 51.6 & 54.4 & 54.9 \\
\hline-8.6 & 59.9 & 80.7 & 72.67 & 91.3 \\
\hline-3.6 & 61.7 & 81.8 & 75.9 & 93.1 \\
\hline 6.38 & 61.7 & 81.8 & 75.97 & 93.1 \\
\hline 16.38 & 61.7 & 81.8 & 75.97 & 93.1 \\
\hline
\end{tabular}

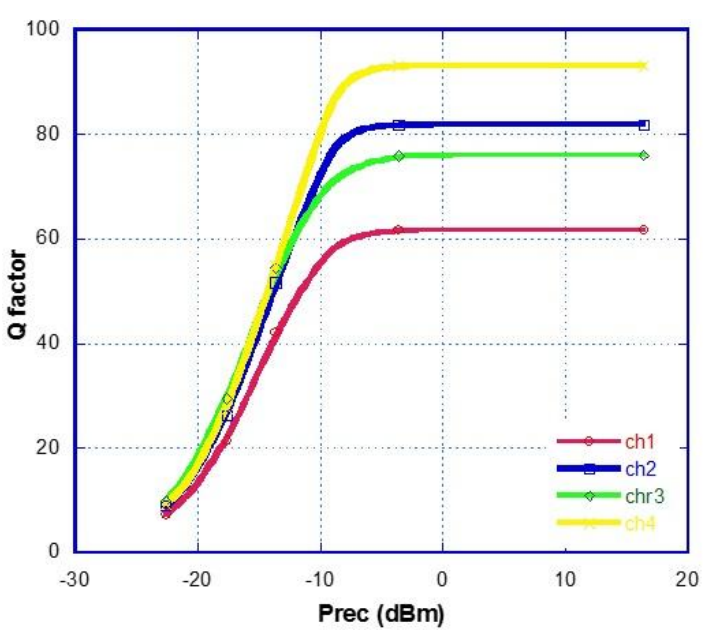

Fig. 2: Simulated Q-factor versus received power at $50 \mathrm{Km}$

\subsection{The Effect of Fiber Length on the Received Power}

The impact of the fiber length on the received power is investigated as shown in table 2 . It is noticed that as the length of the fiber is increased, more power would be needed to achieve the same Q factor of 8, as seen in Fig. 3.

Table 2. The $Q$ factor of each channel at different lengths of the fiber

\begin{tabular}{|c|c|c|c|c|}
\hline $\begin{array}{c}\text { Length } \\
(\mathbf{K M})\end{array}$ & $\begin{array}{c}\text { Received } \\
\text { power } \\
\text { (ch1) }\end{array}$ & $\begin{array}{c}\text { Received } \\
\text { power } \\
\text { (ch2) }\end{array}$ & $\begin{array}{c}\text { Received } \\
\text { power } \\
\text { (ch3) }\end{array}$ & $\begin{array}{c}\text { Received } \\
\text { power } \\
\text { (ch4) }\end{array}$ \\
\hline 20 & -22.6 & -24 & -24.3 & -24.6 \\
\hline 40 & -22 & -23.7 & -24.1 & -23.8 \\
\hline 60 & -21.7 & -23.4 & -23.8 & -24 \\
\hline 80 & -21.4 & -23.2 & -23.6 & -23.8 \\
\hline 100 & -21.1 & -23 & -23.4 & -23.6 \\
\hline
\end{tabular}

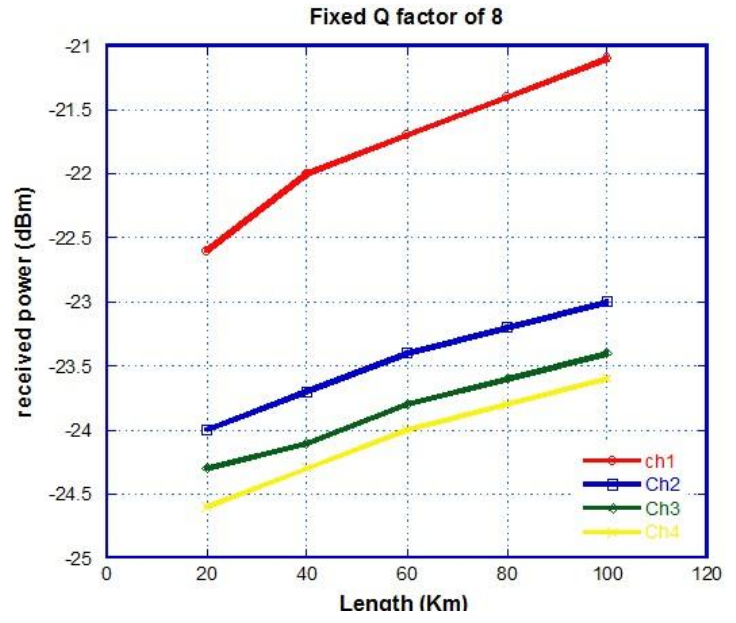

Fig. 3 The relation between the length and received power 


\subsection{The Effect of the Frequency Spacing on the $\mathbf{Q}$ factor}

The impact of Frequency spacing on the $\mathrm{Q}$ factor was also investigated. Note in Fig. 4.A the Q factor for different channel spacing at data rate of $10 \mathrm{~GB} / \mathrm{s}, 25 \mathrm{~km}$.

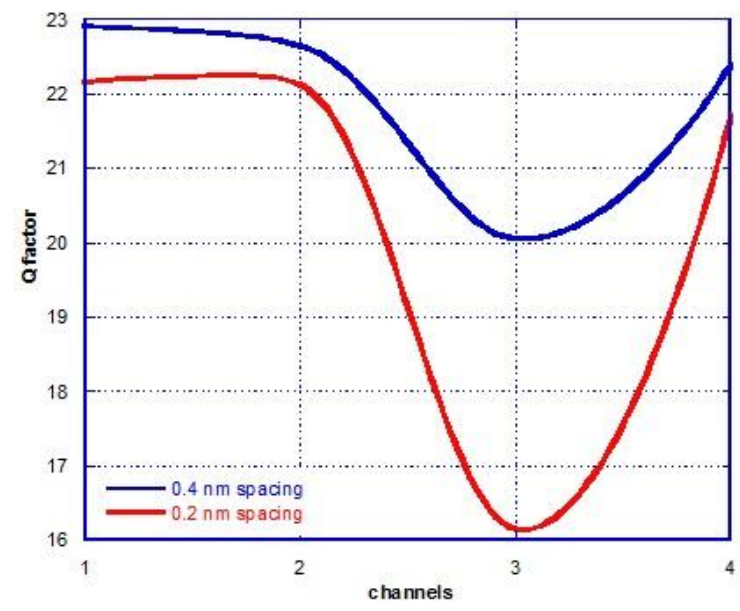

Fig. 4-A: The $Q$ factor for different channel Spacing at data rate of $10 \mathrm{~Gb} / \mathrm{s}, 25 \mathrm{~km}$

In addition, the eye diagram of channels at different frequency spacing is presented in Fig 4.B

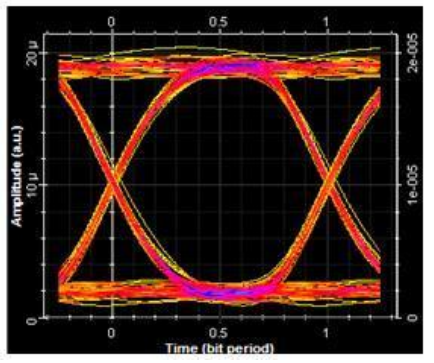

Frequency spacing $25 \mathrm{Ghz}$ $(0.2 \mathrm{~nm}), \mathrm{Q}=22.9$

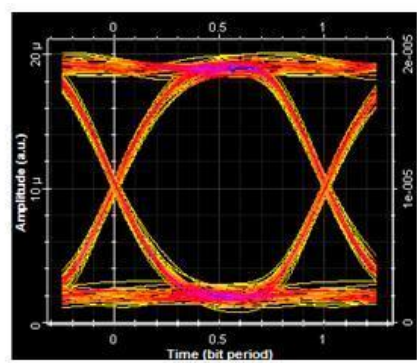

Frequency spacing $50 \mathrm{Ghz}$ $(0.4 \mathrm{~nm}), \mathrm{Q}=23.16$
Fig 4-B: The Eye diagram for different channel Spacing at data rate of $10 \mathrm{~Gb} / \mathrm{s}, 25 \mathrm{k}$

\subsection{The Effect of the Transmitted Power of the Added/dropped Channel}

Figure 5 shows the effect of the transmitted power of the added/dropped channels. It can be seen that increasing the added/dropped channel power results in high Q-factor of this channel, and a slight change in the Q-factor of the other channels. Furthermore it can be observed that adding/dropping either the first or the last channel would results in the highest Q-factor.

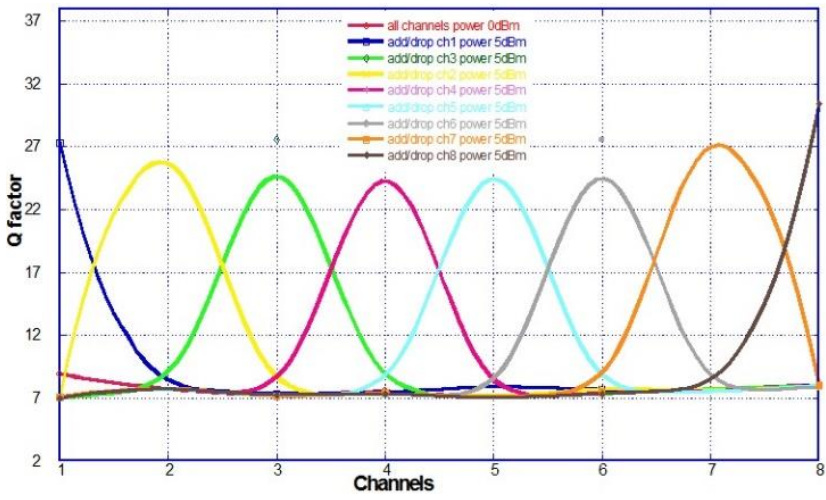

Fig.5: The $Q$ factor of different channels at different Transmitted power at $100 \mathrm{~km}$

In addition, a network was simulated to find the least power needed for all the added/dropped channels to achieve $\mathrm{Q}$ factor of 6 at $1 \mathrm{~Gb} / \mathrm{s}$ and $100 \mathrm{~km}$. As shown in figure 6 the least received power required in this network to achieve $Q$ factor of 6 (BER of $10^{-9}$ ) is $2 \mathrm{dBm}$, which is equivalent to $0.63 \mathrm{mw}$.

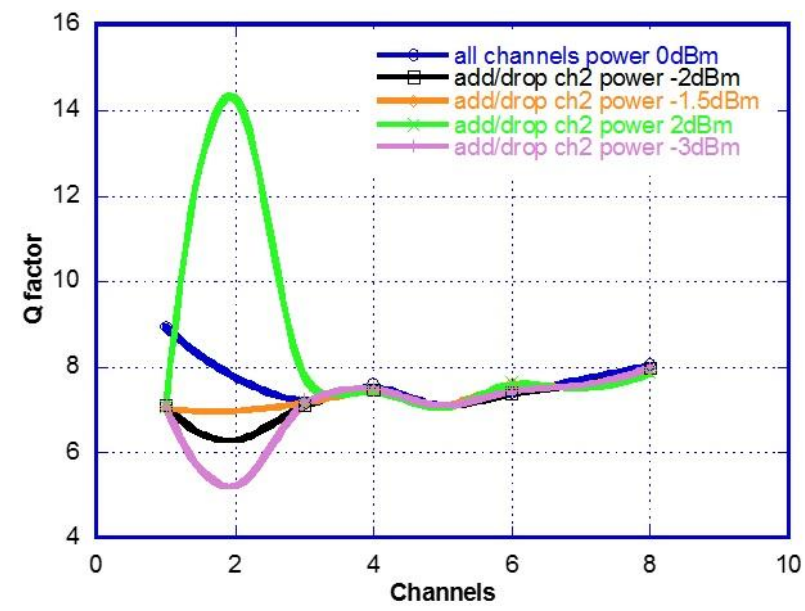

Fig. 6 the $Q$ factor of all channels at different Transmitted power

\section{CONCLUSION}

In this paper, the transmission Performance over fiber transmission system is investigated considering impact of added/dropped channels, transmitted and received power, frequency spacing, and fiber length. From the simulation work it is found that the added/dropped channel has the lowest $\mathrm{Q}$ factor, and that is mainly due to the interference. It was also noticed that as the frequency spacing between the transmitted channels decreases, the Q-factor also decreases. Another thing is that as the received power increases, the $\mathrm{Q}$ factor also increases, until a certain value; the Q-factor reaches the saturation and would be constant no matter how much the power is increased, and that is mainly due to the fiber nonlinearity.
Also as the length of the fiber increases, more power is needed to achieve the Q-factor of 6 . Besides that, it is found 
that the channel where adding/dropping occurs needs more power to achieve the Q-factor of 6, at the same length. Finally the increase of the added/dropped channel power results in high Q-factor of this channel, and a slight change in the Qfactor of the other channels. Furthermore it can be observed that adding/dropping either the first or the last channel would results in the highest Q-factor, and that is because these channels have less interference than the remaining channels.

\section{REFERENCES}

[1] Rajiv Ramaswami and Kumar N. Sivarajan, "Optical Networks", Morgan Kaufmann, USA, 2002 Second Edition.

[2] Govind p. Agarwal, "Fiber Optic Communication Systems”, Wiley Interscience, New York 2002.

[3] IEEE/OSA J. Lightwave Technol., System Issues For WDM Components, vol.14, no. 6, 1996.
[4] Biswanath Mukherjee," Optical WDM Networks", Springer Science+Business Media, USA, 2006.

[5] Mukherjee, "WDM Optical Communication Networks: Progress and Challenges," IEEE Journal On Selected Areas In Communications, vol. 18, no. 10, pp. 18101824,2000

[6] IEEE/OSA J. Lightwave Technol., Performance Issues in WDM Networks, vol., no., 19.

[7] Bob Chomycz, "Planning Fiber Optic Networks", McGraw- Hill, New York 2009.

[8] Biswanath Mukherjee," Optical WDM Networks", Springer, USA 2006.

[9] Ivan Kaminowand Tingye Li, “optical fiber telecommunications IVB systems and impairments", Academic Press, USA, 2002. 